\title{
Study of Zinc Deposited in the Presence of Organic Additives for Zinc-based Secondary \\ Batteries
}

CHLADIL, L.; ČECH, O.; SMEJKAL, J.; VANÝSEK, P.

Journal of Energy Storage

Volume 21, February 2019, Pages 295-300

ISSN: 2352-152X

DOl: https://doi.org/10.1016/j.est.2018.12.001

Accepted manuscript

(C) 2019. This manuscript version is made available under the CC-BY-NC-ND 4.0 license

http://creativecommons.org/licenses/by-nc-nd/4.0/ 


\title{
Study of Zinc Deposited in the Presence of Organic Additives for Zinc-Based Secondary Batteries
}

\author{
$\underline{\text { L. Chladil }}^{\mathrm{a}, \mathrm{b}}$, O.Čech ${ }^{\mathrm{a}, \mathrm{b}}$, J. Smejkal ${ }^{\mathrm{a}}$ and P. Vanýsek ${ }^{\mathrm{a}, \mathrm{b}}$ \\ a Department of Electrical and Electronic Technology, Brno University of Technology, \\ Technicka 10, 61600 Brno, Czech Republic \\ ${ }^{\mathrm{b}}$ Centre for Research and Utilization of Renewable Energy, Faculty of Electrical \\ Engineering and Communication, BUT, Technicka 10, 61600 Brno, Czech Republic
}

\begin{abstract}
This work is focused on the effect of selected organic additives on zinc deposit properties in relation to a possible utilizing the additives for a zinc based battery systems worked with alkaline electrolyte. The Zn layers were deposited on tin substrate from the $\mathrm{KOH}$ based electrolytes saturated by zinc oxide and with addition of different organic surfactants - CTAB, Slovasol 2520/2, Tween 20 and Lugalvan G 35 in concentration $500 \mathrm{ppm}$. Depositions were held under low current densities $10 \mathrm{~mA} / \mathrm{cm}^{2}$ where the mossy porous deposit grows from pure $\mathrm{KOH}$ solutions. All additives were examined with emphasis on the study of zinc deposit morphology and their ability to create uniformly distributed porous structure which could exhibit fast electrode kinetic. All deposits were studied by X-ray crystallography and preferred structure orientations are reported. For the purpose of using additives directly in the battery systems we evaluated also the corrosion properties of the $\mathrm{KOH}$ solution with addition of the above mentioned surfactants. It has been found that the presence of CTAB and Slovasol 2520/2 lead to a pyramidal texture, Lugalvan G 35 produced micro-crystalline deposit with opened porous structure and finally presence of Tween 20 lead to nano-crystalline highly porous deposit almost without preferred orientation.
\end{abstract}

\section{Introduction}

Electrochemical deposition of zinc is a process utilized mainly in plating industry and in the field of energy storage. Although electrodeposition of zinc to form a protective layer is still more commercially exploited and therefore is more widely studied [1], [2], [3], development of unconventional electrochemical energy storage (EES) systems that could be based on zinc electrodes [4] brings a new impetus to study the zinc deposition upon the conditions of these battery systems. Using zinc for energy storage seems to be prospective mainly due to its abundance, low cost and ease of recycling. This gives an advantage of the zinc based system over conventional Li-ion [5] or vanadium redox flow batteries [6], [7]. The group of zinc based energy storage systems is wide and contains long-term investigated nickel zinc cells [8], [9], zinc-silver [10] and many different types of zincbased hybrid flow batteries like zinc-air, zinc-iron, zinc-cerium, zinc-iodine, zinc-bromine, zinc-polymer etc. [11]. Although both application fields - plating industry and battery systems have different requirements on zinc deposits (corrosion protection needs a compact zinc layer without porosity whereas battery application benefits form high surface structures with fast reaction kinetics and good diffusion properties) they are united in the effort to avoid dendritic growth of zinc. Growth of zinc dendrites occurs mainly at high current densities and depends on the concentration of soluble zinc ions. 
During cathodic polarization of the zinc electrode the zincate ions start to reduce to metallic zinc. In this process, the zinc is deposited from the electrolyte to the current collector of the negative electrode. The reagents are in the form of zincate ions $\mathrm{Zn}(\mathrm{OH}) 42-$ diluted in the solution and in the electrode are in the form of $\mathrm{ZnO}$ [12]. The total deposition morphology is highly dependent on current densities at which the dendritic growth occurs [13]. Suppression of the dendritic growth is possible under the conditions supporting transport of zinc ions such as increase concentration of zinc ions in the electrolyte and low viscosity of the electrolyte or forced electrolyte convection in the case of flow-batteries.

Another way how to avoid dendrite formation is a controlled zinc deposition by special current profile [14], [15], [16], [17]. This approach was broadly studied for Ni-Zn or Ni-air battery applications [15], [17], [18] and the current profile typically consists of high current pulses complemented by electroless periods and in some cases also by counterpulses. While the deposition at high current peak ensures a sufficient level of overpotential for zinc crystal growth in all crystallographic direction, the currentless gaps were used as recovery times when the created diffusion layer gets the time to balance the reactant gradient, and finally, the high current counter-pulses should dissolve the tips of the dendrites and redeposit the dendrite material in a level form on the electrode. For example Lin et al. used the pulses for preparation of a zinc-air anode and they found the best results for a $500 \mathrm{~Hz}$ frequency [17] which is consistent with our previous results [16].

The other approach for inhibition of dendrite formation is utilizing of special organic additives (surfactants) that should prevent a non-uniform zinc deposition and thus keep up the smooth and bright surfaces without dendrites [19], [20]. The surfactants have the ability to form a barrier for the reactants (zincate) on the electrode surface, thereby balancing their uneven deposition on the surface of the electrode. This phenomenon is called a blocking effect [19]. The surfactant molecule typically has a hydrophilic and hydrophobic part. The hydrophobic part is oriented towards the solid surface. By adsorbing on a solid surface, it creates a barrier which prevents access of the ions to the surface of the electrode. This at higher current densities leads to suppression of the preferred growth of dendrites. For this reason, zinc deposition will begin to slow down. Impact of the rate of electron transfer includes blocking of active sites using surfactants and electrostatic interaction between electroactive particles of zinc ions and absorbed surfactants [14]. As a result we can obtain a porous layer without the presence of dendrites. Not only surfactants, but also other metal ions, and organic and inorganic compounds are important additives that can affect the shape and size and thus change the morphology of the deposit [21], [22].

As a result, both approaches, pulse charging and using of additives, could effectively reduce dendrite formation and both were applied on zinc-based EES systems. Our contribution aims to extend the group of usable surfactants that are able to create a highly porous structure without any presence of dendrites. Additives for this study have been selected based on their already known benefits for Ni-Zn cell (CTAB), based on their using in galvanic industry (Lugalvan G 35) and based on our previous research project in the field of Ni-Zn accumulators. Deposits were evaluated from their structural properties using X-ray crystallography with emphasis on evaluation of a preferred orientation. Influence of additives on corrosion properties of zinc were study on wire zinc electrode in order to investigate changes in corrosion behavior of alkaline environment enrich by selected additives.

\section{Material and Methods}

Current collectors for deposition were prepared from a rolled tin ( $\mathrm{Sn}$ ) sheet of $0.5 \mathrm{~mm}$ thickness. Tin metal has been chosen because of its high value of over-potential 
for hydrogen evolution and because its internal (crystallographic) structure is similar to metallic zinc. The requirement for another collector material than zinc is based on the need to measure the deposit parameters and it is therefore necessary to distinguish the structure of the underlying material and the deposit in the diffractogram. The measuring area was $2 \mathrm{~cm}^{2}$; the remaining part of the electrode was insulated with an epoxy adhesive and then cured at $100{ }^{\circ} \mathrm{C}$ for 60 minutes.

The basic solutions were prepared by dissolving $30 \mathrm{~g} \mathrm{ZnO}$ in $1000 \mathrm{ml}$ of $6 \mathrm{~mol} / \mathrm{dm}^{3} \mathrm{KOH}$. The solution was close to a saturated state, which corresponds to the state of the electrolyte in alkaline batteries at the end of the discharging process. Tested solutions were prepared from stock solutions by adding additives. More information about chemical composition and distributor of used additives is in Table 1.

Table 1. Chemical composition and application field of selected additives.

\begin{tabular}{|c|l|l|}
\hline Additives & Chemical composition & More details \\
\hline CTAB & $\begin{array}{l}\text { cetyltrimethylammonium } \\
\text { bromide }\end{array}$ & $\begin{array}{l}\text { Cationic surfactant, used in the synthesis of } \\
\text { gold nanoparticles. It is supplied by Sigma- } \\
\text { Aldrich. }\end{array}$ \\
\hline Slovasol 2520 & alkylpolyglycolether & $\begin{array}{l}\text { Aqueous solution. Is used as a zinc bath polish } \\
\text { in the galvanic industry. It is supplied as a 50\% } \\
\text { solution by BASF company. }\end{array}$ \\
\hline Tween 20 35 & $\begin{array}{l}\text { Product could be used a corrosion inhibitor and } \\
\text { in the cosmetics industry. Supplied by } \\
\text { Slovchema. }\end{array}$ \\
\hline & solyoxyethylene & $\begin{array}{l}\text { Non-ionic detergent widely used for stable oil- } \\
\text { in-water emulsion in the cosmetics industry. It } \\
\text { was supplied by Sigma-Aldrich }\end{array}$ \\
\hline
\end{tabular}

Selected additives contains both nonionic (Slovasol 2520/2 and Tween 20) and cationic surfactants (CTAB) and also industrial additive used in galvanic zinc plating (Lugalvan G 35). The additives were added to the solution in concentration $500 \mathrm{ppm}$ by weight. For solutions was used demineralized water with specific conductivity $0.1 \mu \mathrm{S} / \mathrm{cm}$.

The zinc deposition was realized in a three-wire connection at a constant current of $10 \mathrm{~mA} / \mathrm{cm}^{2}$ for 30 minutes. The working electrode was a tin electrode, a zinc wire was used as the reference electrode and the counter electrode was a nickel wire mesh. The counter electrode had a 2.5 times larger area than the working electrode. Upon completion of the deposition, the electrodes were removed from the solution and placed into a large vessel of distilled water for 1 minute to remove the alkaline solution and additives from the deposits. Thereafter, the electrodes were placed in a constant temperature chamber and dried for 48 hours at $40{ }^{\circ} \mathrm{C}$.

The corrosion tests were also performed in a three-wire connection, but as the reference electrode a standard calomel electrode was used and as a working electrode a $10 \mathrm{~mm}$ long zinc wire of $2 \mathrm{~mm}$ diameter was used (active surface $0.659 \mathrm{~cm}^{2}$ ). The electrolytes for the corrosion tests were based on pure $6 \mathrm{~mol} / \mathrm{dm}^{3} \mathrm{KOH}$ without any zincate ions. Only additives in 500 ppm concentrations were added.

X-ray measurement was performed by Rigaku Miniflex $600 \mathrm{HR}$ with selected $\mathrm{k} \beta$ filter of $0.003 \mathrm{~mm}$ thickness and a $0.1 \mathrm{~mm}$ divergence slit. The measuring range was from $20^{\circ}$ to $120^{\circ}$ with a step $0.02^{\circ}$. Measurements were made on samples that were placed on a low background holder without any X-ray reflections. Particle sizes were calculated using the Scherrer equation: 


$$
D=\frac{K \lambda}{\beta \cos \theta}
$$

where $D$ is the mean size of the crystallite, shape factor $K$ was $0.9, \beta$ is the line broadening at half maximum intensity (referred also as FWHM) and $\theta$ is the Bragg angle [23]. For crystallites size calculation of samples with strong preferred orientation we subtracted $\beta$ from the peaks with the highest intensity.

Morphology was studied on scanning electron microscope Vega $3 \mathrm{XMU}$ with $\mathrm{LaB}_{6}$ Cathode by Tescan. All pictures were obtained in vacuum and with accelerating voltage $20 \mathrm{kV}$.

\section{Zinc Deposition}

\section{Results and Discussion}

Zinc deposition is close to the process inside a zinc based flow-battery during charging. Battery charging could proceed in two regimes: constant current (galvanostatic) or constant potential (potentiostatic). The second mentioned is typically used during final stage of battery charging in order to prevent increase of hydrogen evolution but usually a battery charging is carried out under galvanostatic control. Therefore we used the galvanostatic mode although potentiostatic regime is typically preferred by investigators for the study of changes in deposit morphology during zinc deposition [19]. If the galvanostatic deposition is under mass-transport control, changes in morphology such as a dendritic growth can be detected by changes (decrease) of potential during the galvanostatic deposition.

The time course of the cathodic potential during the galvanostatic deposition is shown in Figure 1. Even though the cathodic potential profile for the deposition from the blank electrolyte seems to be almost linear, the second part of the curve $(t>0.3 \mathrm{~h})$ exhibits a decreasing trend and the cathodic potential at the end of deposition is reduced to $75 \%$ of the maximum cathodic overpotential. It indicates the formation of a more-open structure in the second part of the zinc deposition. Indeed, Figure 2 revealed the formation of mossy porous irregularly shaped bunches that start to growth on the compact zinc deposit. This is the typical structure obtained mainly at low-current densities when the overpotential of the deposition decreases under the level of a more-dimensional nucleation. This overpotential drop may not be evident from the measured curves because it can be only a local effect occurring particularly in the surface dimples or depressions. 


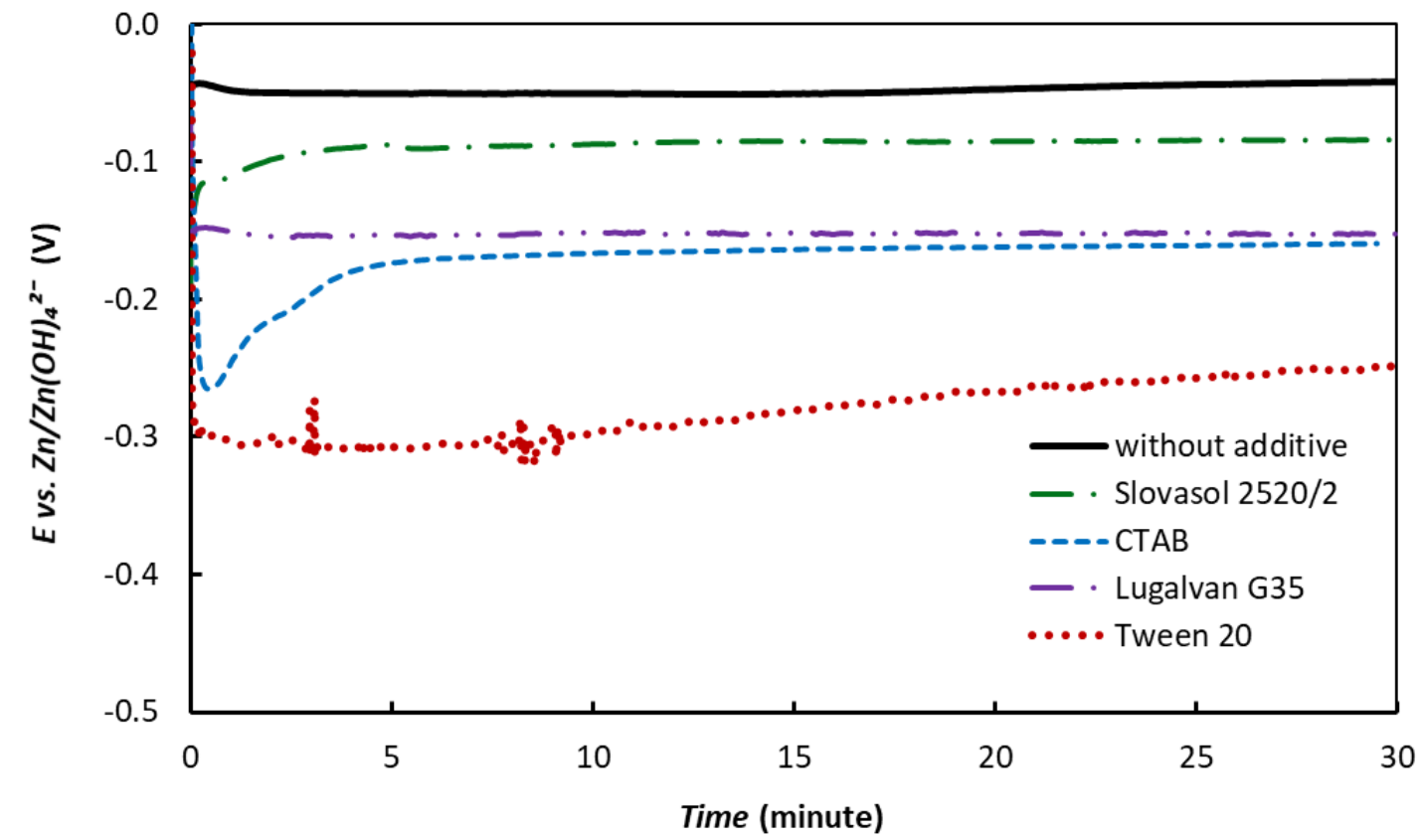

Figure 1. Voltage-time profile at galvanostatic deposition $\left(j=10 \mathrm{~mA} / \mathrm{cm}^{2}\right)$ for electroplating zinc layers in blank electrolyte $\left(6 \mathrm{~mol} / \mathrm{dm}^{3} \mathrm{KOH}+30 \mathrm{~g} / \mathrm{dm}^{3} \mathrm{ZnO}\right)$ and electrolyte with addition of additives with a concentration of 500 ppm at current densities $10 \mathrm{~mA} / \mathrm{cm}^{2}$.

\section{Deposit Morphology}

Morphology of the zinc deposit obtained by a scanning electron microscope is shown in Figure 3. The most stable potential profile exhibits the additive Lugalvan G 35, where only small decline of the cathodic potential during the first $90 \mathrm{~s}$ could be identified (Figure 3). It is caused by initial changes in porosity of the zinc layer shortly after zinc nucleation that is on the other hand stable throughout the deposition.

Potential during deposition in the electrolyte with addition of Slovasol 2520/2 and CTAB were stabilized over a longer period of time $(\approx 6$ minutes $)$. Initial cathodic overpotential increases rapidly in the first seconds and then is reduced to $60 \%$. Morphology of the deposits in Figure 3 revealed the presence of crystallite clusters of diameter tenths of micrometers. The tin substrate of the electrode deposited in Slovasol $2520 / 2$ in some part exhibits the presence of thin grooves that are the remains of surface polishing. Thus it reveals that the electrode contains sites that are not covered by a zinc deposit and most of the zinc volume is stored in these clusters. Formation of these clusters will most likely be the reason why the cathodic overpotential decreases in the first stage of deposition.

Deposition in the presence of Tween 20 has occurred at the highest cathodic overpotential which reached $310 \mathrm{mV}$. Presence of the spikes in the potential profile indicates presence of hydrogen evolution (bubble formation) to some extent. High overpotential slowly decreases during the whole deposition. The SEM images in Figure 3 revealed the presence of isolated spongy-like clumps placed on a slightly covered tin substrate by zinc particles. Growth of the clumps and increasing of the electrode surface could be found in relation to overpotential decline. Regarding the large changes the microporosity (obvious from the details of surface in the right pictures of Figure 3) we can assume that gradual decrease in the cathodic overpotential are more likely caused by 
macroscopic changes in the electrodes surface (growth of clusters, clumps or large dendrites) then by an increase of active surface due to higher micro- or nano-porosity of the layer.

High overvoltage of the electrode in respect to the zinc equilibrium potential (especially in the case of Tween 20) expresses loss of charging energy and thus reduces the efficiency of energy storing. It has to be considered more mainly in the battery systems with low value of the cell voltage.
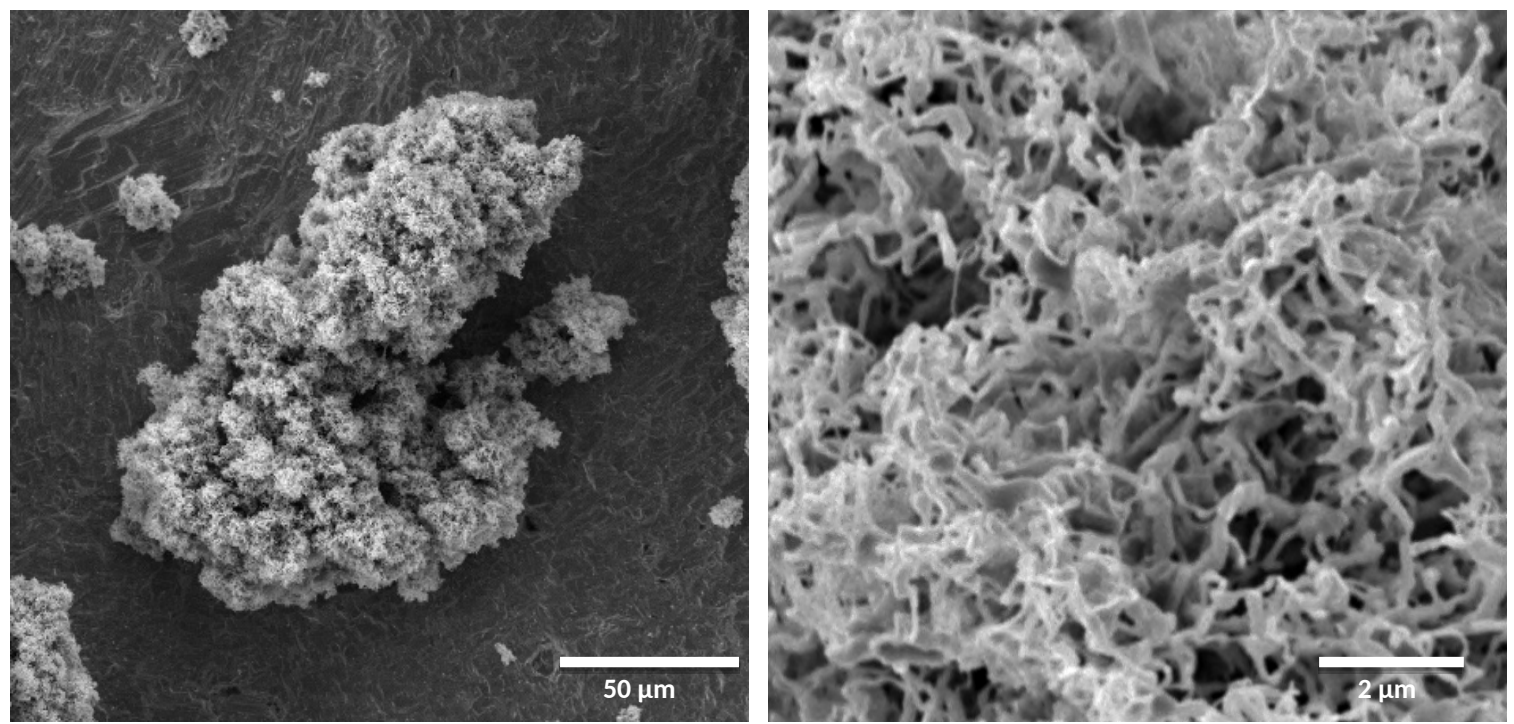

Figure 2. Zn deposit obtained from $6 \mathrm{~mol} / \mathrm{dm}^{3} \mathrm{KOH}$ solution saturated with $30 \mathrm{~g} / \mathrm{dm}^{3}$ $\mathrm{ZnO}$ at current densities $10 \mathrm{~mA} / \mathrm{cm}^{2}$. 

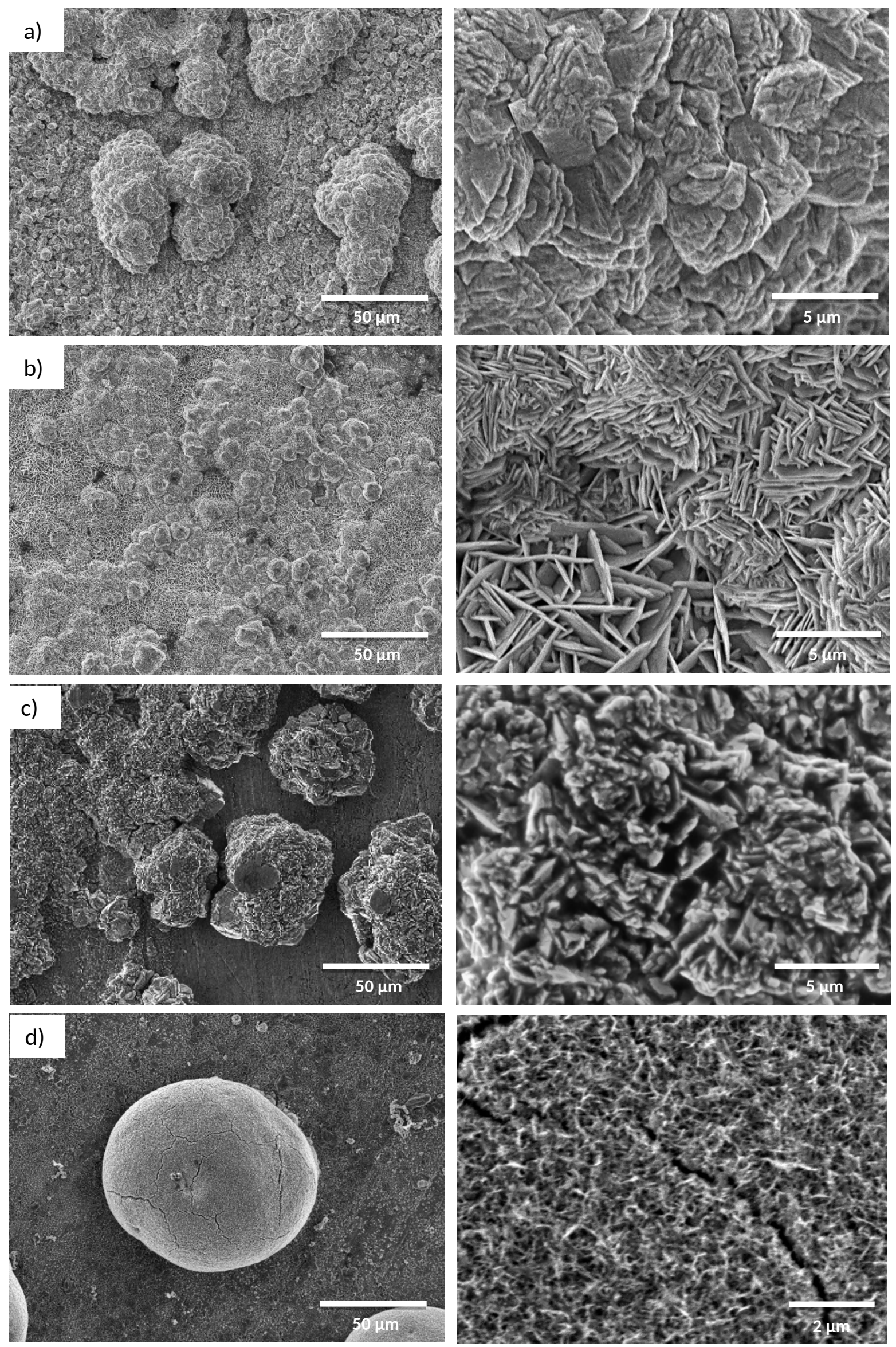
Figure 3. Deposit structures at current densities $10 \mathrm{~mA} / \mathrm{cm}^{2}$. Blank solution was $6 \mathrm{~mol} / \mathrm{dm}^{3} \mathrm{KOH}+30 \mathrm{~g} / \mathrm{dm}^{3} \mathrm{ZnO}$. Selected additives were a) CTAB, b) Lugalvan $\mathrm{G} 35$, c) Slovasol 2520/2 d) Tween 20 and were added in concentration of 500 ppm. The images on the right are a detailed view of the surfaces taken at the cluster features on the left side.

\section{Deposit XRD Evaluation}

Detailed SEM pictures of zinc deposits in Figure 3 (right) reveal important changes of micro-porosity and texture of zinc, when organic additives are present. This is also confirmed by the Rietveld simulation of the obtained diffraction patterns (Figure 4). We analyzed the preferred orientation of the zinc deposit and the resulting March coefficients (MC) for selected crystallographic planes which are summarized in Table 2. It should be noted that when MC is higher than 1 it indicates a decrease of reflection in the selected crystallographic directions and vice versa, MC below 1 indicates higher reflection in the selected planes. Silva Filho and Lins [3] studied the crystallographic texture of an electrodeposited zinc layer through a wide range of current densities from $150 \mathrm{~mA} / \mathrm{cm}^{2}$ to $1500 \mathrm{~mA} / \mathrm{cm}^{2}$. They identified a significant changes in reflection of basal (0002) plane and pyramidal (10 $\overline{1} 5),(10 \overline{1} 2)$ and (10 11$)$ planes when the current density was increasing (in the present article the planes are described using the standard Miller-Bravais notation). Our depositions proceeded at much lower currents $\left(10 \mathrm{~mA} / \mathrm{cm}^{2}\right)$ and for longer time period. Presence of additives dramatically increases overpotential for the deposition which could be similar to higher current condition.

Deposit grown in the blank electrolyte is compactly layered with mossy porous zinc clumps. Best fits of the Rietveld simulation (error parameters $\mathrm{Rp}<10$ ) were obtained for selected basal (0002) plane and the MC was slightly above 1.2 that indicates slight decrease in relative intensity of the selected plane. Similar results were obtained by Silva Filho and Lins [3] still at current densities $150 \mathrm{~mA} / \mathrm{cm}^{2}$. The bright surface appearance of electrode is also typical feature of deposit with basal texture.

In the case of the CTAB additive, the deposited zinc structure has grown over the entire surface of the electrode in pyramidal-like structures. Indeed, the results of the Rietveld refinement revealed significant depression of the $(10 \overline{1} 5)$ plane, which is a typical feature of zinc deposit obtained at high current densities.

Lugalvan G 35 additive resulted in a deposited layer composed of insulated particles in the shape of small scales. The detail of the scales is shown in Figure $3 \mathrm{~b}$ ). These scales were arranged close to each other and were grown perpendicularly to substrate i.e. in the direction of the reactant flow. XRD diffraction pattern and value of the MC revealed the strongest preferred orientation of deposit in comparison to other deposits. Strong reflection from the pyramidal plane (10 $\overline{1} 1$ ) expressed by value of MC 0.467 is a typical feature of a strongly pyramidal surfaces typically obtained at current densities around $1500 \mathrm{~mA} / \mathrm{cm}^{2}$ achieved by agitation of the electrolyte. Zinc layers composed of thin scales will have the large surface area due to partially opened structure.

Microstructure of deposit obtained using Slovasol 2520/2 seems to be similar to the zinc layer deposited in the presence of CTAB but a much stronger X-ray reflection from the pyramidal (1012) plane was detected. Deposition was performed at lower values of overpotential in respect to the other additives and high intensity of the (1012) plane corresponds to the deposit obtained at middle current densities of $600 \mathrm{~mA} / \mathrm{cm}^{2}$.

The additive Tween 20 produces clusters that were made up of small sticks. A detail of the small sticks is shown in Figure $3 \mathrm{~d}$ ) (right). Circular shapes of the clusters indicate that the growth of these clusters was identical in every direction. Because the clusters are 
created of sticks, the structure is highly porous and good dissolved reactant access properties are expected. The deposition proceeded at high overvoltage but surprisingly the deposit exhibits only small preferred orientation in the (1015) plane. It could be concluded that from the structural point of view we obtained almost the same X-ray patterns as in the case of randomly oriented powder zinc.

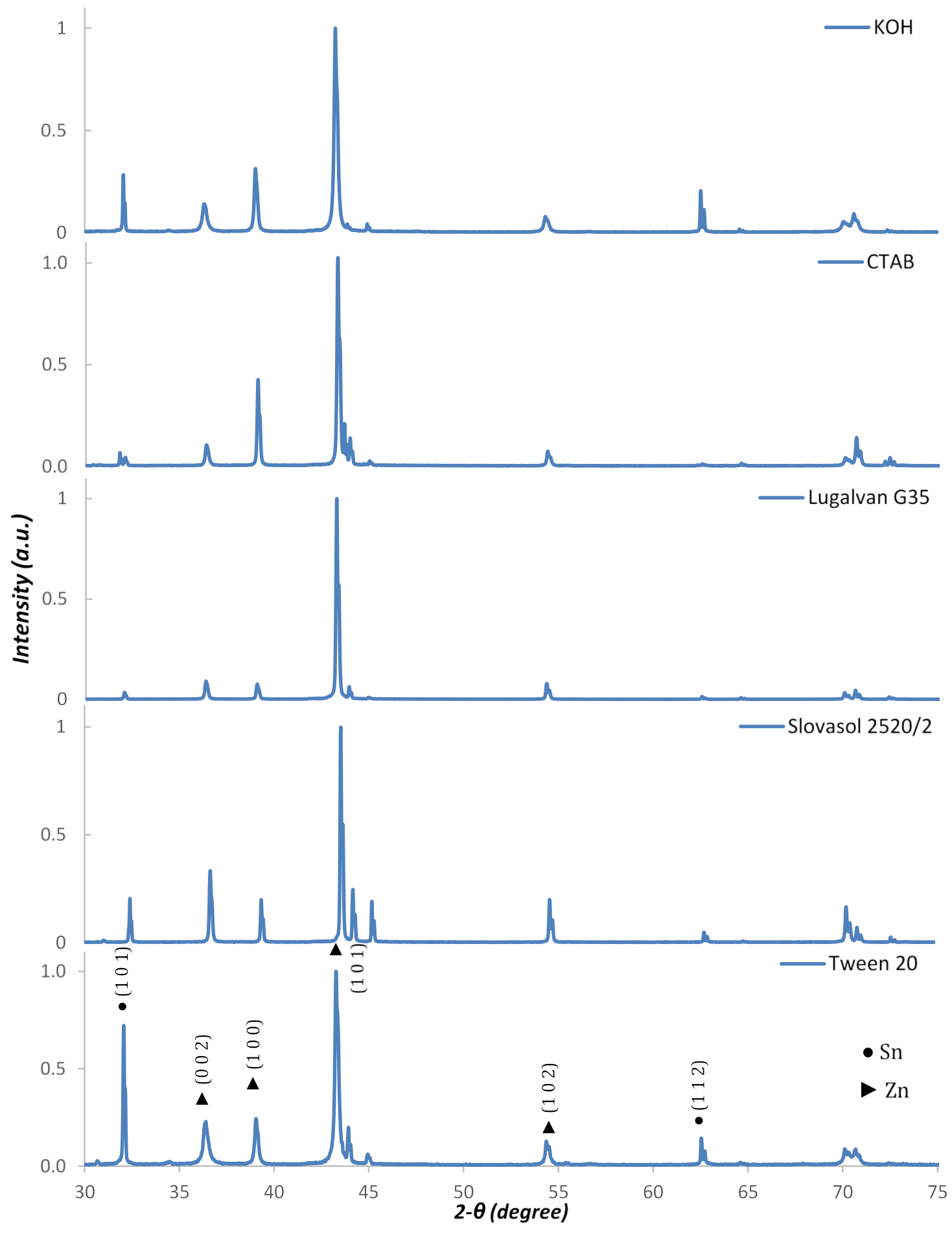

Figure 4. Diffraction spectrum for samples of Zn deposits from the solution $6 \mathrm{~mol} / \mathrm{dm}^{3}$ $\mathrm{KOH}$ saturated with $30 \mathrm{~g} / \mathrm{dm}^{3} \mathrm{ZnO}$ with added organic additives at current densities of $10 \mathrm{~mA} / \mathrm{cm}^{2}$. 
Table 2. Preferred orientation of the deposited layers grown with addition of additives. The preferred tin substrate orientation had the same orientation for each additive (112 2$)$.

\begin{tabular}{|c|l|c|c|c|c|c|}
\hline & & KOH & CTAB & Lugalvan G 35 & Slovasol 2520/2 & Tween 20 \\
\hline \multirow{3}{*}{ Zinc } & $\mathrm{h}$ & 0 & 1 & 1 & 1 & 1 \\
\cline { 2 - 7 } & $\mathrm{k}$ & 0 & 0 & 0 & 0 & 0 \\
\cline { 2 - 7 } & $\mathrm{k}^{\prime}$ & 0 & $\overline{1}$ & $\overline{1}$ & $\overline{1}$ & $\overline{1}$ \\
\cline { 2 - 7 } & $\mathrm{I}$ & 1 & 5 & 1 & 2 & 5 \\
\cline { 2 - 7 } & March coefficient & 1.232 & 1.549 & 0.467 & 0.582 & 1.075 \\
\hline \multirow{2}{*}{ Tin } & March coefficient & 0.331 & 0.610 & 0.447 & 0.444 & 0.412 \\
\hline
\end{tabular}

Insulated clusters were detected in the case of CTAB, Slovasol and TWEEN 20 as additives and their effect is in relation to the slow nucleation process on the tin surface. Whereas tin substrate in the case of CTAB and Slovasol 2520/2 exhibits the deposition of zinc between these clusters, in the case of Tween 20 the tin surface in this area seems to be almost without zinc deposit. It could be due to slow nucleation at the start of the deposition and this effect could be avoided by using high current pulses during the deposit initiation phase.

\section{Effects of Additives on Corrosion}

Evaluation of corrosion parameters and hydrogen evolution is the final part of our study. It is known that corrosion resistance depends on preferred crystallographic plane and the corrosion rate is lower for planes where zinc is surrounded by higher amount of other zinc atoms. Thus corrosion resistance decreases in the following order of crystallographic planes $\{0001\}>\{1011\}>\{1120\}>\{1010\}$ [24]. Investigation of both effects, corrosion and hydrogen evolution, is important especially when using of an additive directly in the battery systems is considered. Because we wanted to characterize the corrosion environment in the presence of an additive rather than investigate the effect of morphologies on corrosion, we performed the test on a zinc wire with defined surface area without porosity. The electrolyte for the corrosion test was without any zincate and the electrode was held on initial cathodic voltage already before electrode immersion in the electrolyte. It eliminates the initial current peak which would be a consequence of deposition of zincate that dissolved from the time before the start of the measurement. Stirring with a magnetic bar (600 rpm) was employed in order to suppress the diffusion controlled phenomenon especially at high ratio of zinc dissolution during the final stage of anodic polarization. The potentiodynamic curves for blank $\mathrm{KOH}$ electrolytes and additives are shown in Figure 5. 


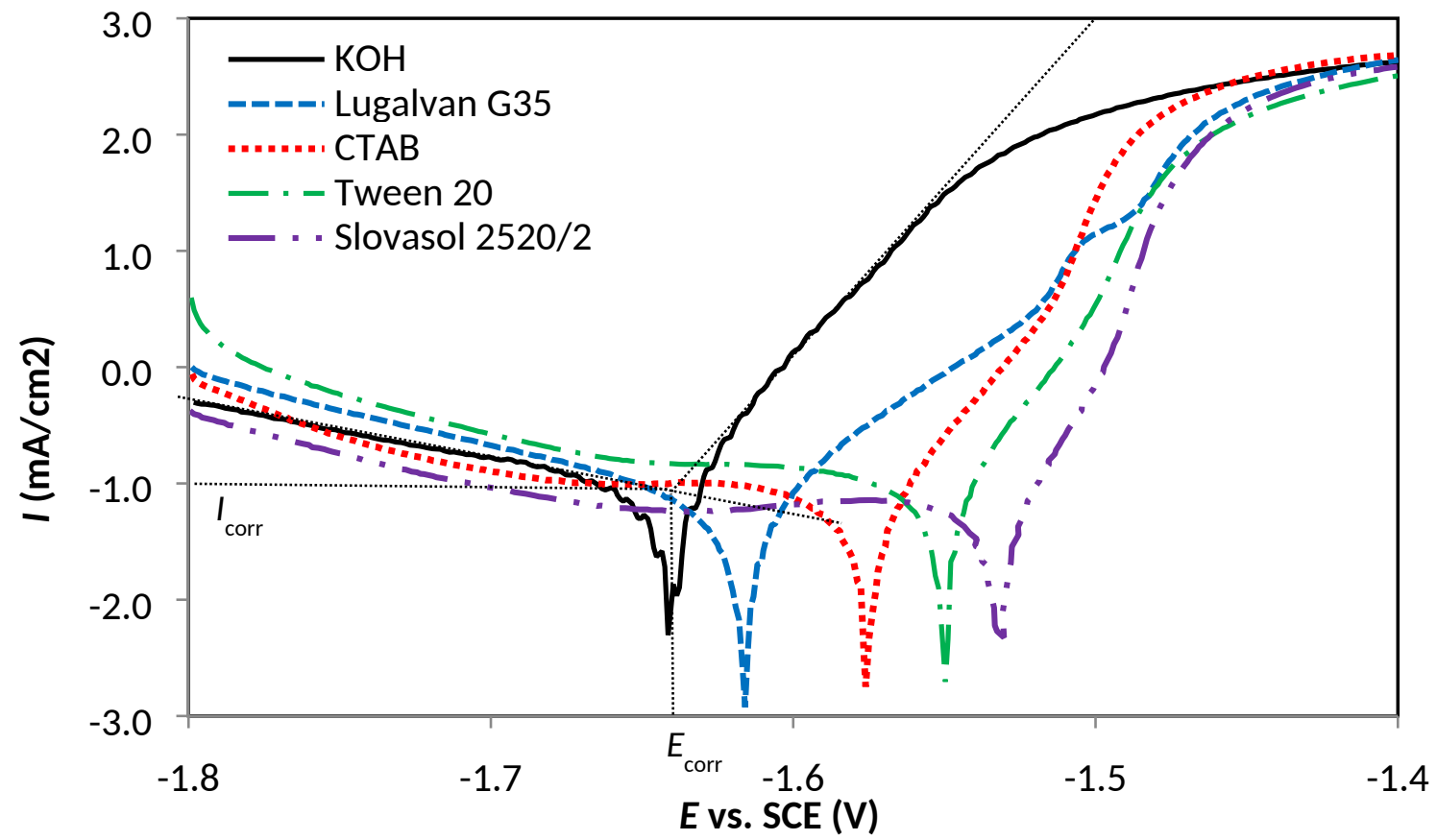

Figure 5. Potentiodynamic curves of zinc electrode in blank $6 \mathrm{~mol} / \mathrm{dm}^{3} \mathrm{KOH}$ and in presence of additives in concentration $500 \mathrm{ppm}$.

Presence of additives completely changes the rates of both electrode reactions hydrogen evolution at cathodic polarization and even more anodic parts when reaction of zinc dissolution proceeds. Subtracted values of corrosion potential $\mathrm{E}_{\text {corr }}$, corrosion current $\mathrm{I}_{\text {corr }}$ and calculated values of corrosion rate (CR) are summarized in Table 3. Last evaluated parameter was the current at potential $-1.75 \mathrm{~V}$ vs. SCE that could point out to value of hydrogen evolution at cathodic overpotential. Parameter $I_{-1,75 \mathrm{~V}}$ is important in order to consider the influence of additives on self-discharging of the zinc-based battery system. Equilibrium potential of zinc electrodes are in the presence of additives shifted to the right side into the less negative values in the following order: blank $\mathrm{KOH}$, Lugalvan $\mathrm{G} 35$, CTAB, Tween 20 and Slovasol 2520/2. In the case of Slovasol 2520/2 the shift exceeded $100 \mathrm{mV}$. It corresponds to typical application field of Slovasol which is designed for corrosion inhibition. The cathodic part of the potentiodynamic curves in the presence of additives can be divided into two regions. One is typically a declining part where the reaction of hydrogen evolution is prevailing and the second one that is closer to corrosion potential could be attributed to the blocking of electrode surface by surfactant. This flatlike plateau typical for passivated surfaces is present in the case of CTAB, Lugalvan G 35 and Slovasol 2520/2. Calculated corrosion rates (Table 3) show the slowest rate for Slovasol 2520/2 and this additive also exhibits the lowest value of hydrogen evolution that could be seen from comparison of the values of parameter $I_{-1.75 \mathrm{~V}}$. The using of additive Slovasol $2520 / 2$ in the battery application could lead to significant reduction of selfdischarging of the battery system and thus allow saving the larger amounts of energy for longer time. 
Table 3. Summarized values of corrosion parameters of the zinc electrodes in blank $6 \mathrm{~mol} / \mathrm{dm}^{3} \mathrm{KOH}$ and in the presence of additives in concentrations of $500 \mathrm{ppm}$.

\begin{tabular}{|c|c|c|c|c|}
\hline Additives & $\begin{array}{c}E_{\text {corr }} \text { vs. SCE } \\
{[\mathrm{V}]}\end{array}$ & $\begin{array}{c}I_{\text {corr }} \\
{\left[\mu \mathrm{A} / \mathrm{cm}^{2}\right]}\end{array}$ & $\begin{array}{c}C R \\
{[\mathrm{~mm} / \text { year }]}\end{array}$ & $\begin{array}{c}I_{-1,75 \mathrm{~V}} \\
{\left[\mathrm{~mA} / \mathrm{cm}^{2}\right]}\end{array}$ \\
\hline- & -1.642 & 83.6 & 0.20 & 0.28 \\
\hline CTAB & -1.574 & 42.6 & 0.10 & 0.27 \\
\hline Lugalvan G 35 & -1.615 & 65.8 & 0.17 & 0.46 \\
\hline Slovasol 2520/2 & -1.531 & 36.7 & 0.09 & 0.19 \\
\hline Tween 20 & -1.549 & 59.8 & 0.14 & 0.61 \\
\hline
\end{tabular}

\section{Conclusions}

Investigated additives have a significant effect on the morphology of deposited zinc at low current densities. For the CTAB, Slovasol 2520/2 and Tween 20 additives, a growth of crystal clusters was observed, whereas using of Lugalvan G 35 produced highly porous deposit around the whole electrode surface.

From crystallographic examination we observed that using CTAB and Slovasol 2520/2 the zinc deposit exhibited a pyramidal texture, Lugalvan G 35 produced micro crystalline deposit with strongly preferred structure according (10 $\overline{1} 2)$ crystallographic plane and finally presence of Tween 20 lead to nano-crystalline deposit almost without preferred orientation. Due to highly porous nature of the deposits performed under presence of Lugalvan G 35 and Tween 20 we can expect good surface access of the prepared layers. Higher overpotential during deposition in the case of Tween 20 has to be considered especially in the case of possible application of additives into a battery system with low value of the cell voltage. This could significantly reduce the cell efficiency.

All additives had the greatest effect on prevention of unevenly grown mossy structure at low current densities and from corrosion study we can conclude that corrosion rate of zinc decreases in the following order $C R_{K O H}>C R_{\text {Lugalvan }{ }_{35}}>C R_{\text {Tween } 20}>C R_{C T A B}>C R_{\text {Slovasol 2520/2. }}$. While Tween 20 and Lugalvan G 35 increased the hydrogen evolution, CTAB and especially Slovasol 2520/2 had an opposite effect and thus could in final application reduce the battery self/discharging.

\section{Acknowledgement}

This research work has been carried out in the Centre for Research and Utilization of Renewable Energy (CVVOZE). Authors gratefully acknowledge financial support from the Ministry of Education, Youth and Sports of the Czech Republic under NPU I programme (project No. LO1210).

\section{References}

[1] E. Budman and R. Sizelove, "Zinc alloy plating", Metal Finishing, vol. 99, no. 1, pp. 334-339, 2001.

[2] K. Youssef, C. Koch and P. Fedkiw, "Improved corrosion behavior of nanocrystalline zinc produced by pulse-current electrodeposition", Corrosion Science, vol. 46, no. 1, pp. 51-64, 2004. 
[3] J. Silva Filho and V. Lins, "Crystallographic texture and morphology of an electrodeposited zinc layer", Surface and Coatings Technology, vol. 200, no. 9, pp. 2892-2899, 2006.

[4] Khor, P. Leung, M. Mohamed, C. Flox, Q. Xu, L. An, R. Wills, J. Morante and A. Shah, "Review of zinc-based hybrid flow batteries: From fundamentals to applications", Materials Today Energy, vol. 2018, no. 8, pp. 80-108, 2018.

[5] O. Cech, J. Thomas, M. Sedlarikova, A. Fedorkova, J. Vondrak, M. Moreno and A. Visintin, "Performance improvement on LiFePO4/C composite cathode for lithiumion batteries", Solid State Sciences, vol. 20, no. 1, pp. 110-114, 2013.

[6] C. Choi, S. Kim, R. Kim, Y. Choi, S. Kim, H. Jung, J. Yang and H. Kim, "A review of vanadium electrolytes for vanadium redox flow batteries", Renewable and Sustainable Energy Reviews, vol. 69, no. 1, pp. 263-274, 2017.

[7] P. Vanysek, V. Novak and L. Chladil, "Investigation of Vanadium Oxidation States in Sulfuric Acid by Voltammetry and Electrochemical Impedance Spectroscopy", ECS Transactions, vol. 70, no. 1, pp. 13-20, 2015.

[8] J. Jindra, "Sealed nickel—zinc cells", Journal of Power Sources, vol. 37, no. 3, pp. 297-313, 1992.

[9] J. Jindra, "Progress in sealed Ni-Zn cells, 1991-1995", Journal of Power Sources, vol. 66, no. 1-2, pp. 15-25, 1997.

[10] Salkind, A. Karpinski and J. Serenyi, "SECONDARY BATTERIES - ZINC SYSTEMS | Zinc-Silver", Encyclopedia of Electrochemical Power Sources, pp. 513523, 2009.

[11] P. Pei, K. Wang and Z. Ma, "Technologies for extending zinc-air battery's cyclelife: A review", Applied Energy, vol. 128, no. 1, pp. 315-324, 2014.

[12] R. Einerhand, "Zinc Electrode Shape Change", Journal of The Electrochemical Society, vol. 138, no. 1, pp. 7-17, 1991.

[13] R. Wang, D. Kirk and G. Zhang, "Effects of Deposition Conditions on the Morphology of Zinc Deposits from Alkaline Zincate Solutions", Journal of The Electrochemical Society, vol. 153, no. 5, pp. C357-, 2006.

[14] Gomes and M. da Silva Pereira, "Pulsed electrodeposition of $\mathrm{Zn}$ in the presence of surfactants", Electrochimica Acta, vol. 51, no. 7, pp. 1342-1350, 2006.

[15] L. Chladil, P. Cudek, V. Novak and P. Dvorak, "Pulse Deposition of Zinc in Alkaline Electrolytes for Ni-Zn Secondary Batteries", ECS Transactions, vol. 63, no. 1, pp. 217-223, 2014.

[16] L. Chladil, O. Cech and P. Vanysek, "Pulse Deposition of Zinc in Electrolytes with Reduced Zinc Oxide Solubility", ECS Transactions, vol. 74, no. 1, pp. 137-146, 2016.

[17] H. Lin, C. Ho and C. Lee, "Discharge performance of zinc coating prepared by pulse electroplating with different frequencies for application in zinc-air battery", Surface and Coatings Technology, vol. 319, pp. 378-385, 2017.

[18] N. Shaigan, W. Qu and T. Takeda, "Morphology Control of Electrodeposited Zinc from Alkaline Zincate Solutions for Rechargeable Zinc Air Batteries", ECS Transaction, vol. 28, no. 32, pp. 35-44, 2010.

[19] C. Lan, C. Lee and T. Chin, "Tetra-alkyl ammonium hydroxides as inhibitors of Zn dendrite in Zn-based secondary batteries", Electrochimica Acta, vol. 52, no. 17, pp. 5407-5416, 2007.

[20] J. Zhu, Y. Zhou and C. Gao, "Influence of surfactants on electrochemical behavior of zinc electrodes in alkaline solution", Journal of Power Sources, vol. 72, no. 2, pp. 231-235, 1998. 
[21] F. Mansfeld and S. Gilman, "The Effect of Tin and Tetraethylammonium Ions on the Characteristics of Zinc Deposition on a Zinc Single Crystal in Aqueous KOH", Journal of The Electrochemical Society, vol. 117, no. 9, pp. 1154-, 1970.

[22] F. Mansfeld and S. Gilman, "The Effect of Lead Ions on the Dissolution and Deposition Characteristics of a Zinc Single Crystal in $6 \mathrm{~N} \mathrm{KOH",} \mathrm{Journal} \mathrm{of} \mathrm{The}$ Electrochemical Society, vol. 117, no. 5, pp. 588-, 1970.

[23] F. Muniz, M. Miranda, C. Morilla dos Santos and J. Sasaki, "The Scherrer equation and the dynamical theory of X-ray diffraction", Acta Crystallographica Section A Foundations and Advances, vol. 72, no. 3, pp. 385-390, 2016.

[24] H. Park and J. Szpunar, "The role of texture and morphology in optimizing the corrosion resistance of zinc-based electrogalvanized coatings", Corrosion Science, vol. 40, no. 4-5, pp. 525-545, 1998. 